\title{
Methylotrophic extremophilic yeast Trichosporon sp.: a soil-derived isolate with potential applications in environmental biotechnology ${ }^{\star}$
}

\author{
Paweł Kaszycki ${ }^{1}$, Kamila Czechowska ${ }^{1}$, Przemysław Petryszak ${ }^{1}$, Jacek \\ Międzobrodzki², Bolesław Pawlik ${ }^{3}$ and Henryk Kołoczek ${ }^{1 凶}$ \\ ${ }^{1}$ Biochemistry Department, University of Agriculture, Kraków, Poland; ${ }^{2}$ Department of Microbiology, Faculty of \\ Biochemistry, Biophysics and Biotechnology, Jagiellonian University, Kraków, Poland; ${ }^{3}$ Department of Mycology, \\ Chair of Medical Microbiology, Collegium Medicum, Jagiellonian University, Kraków, Poland; \\ ®e-mail: koloczek@ogr.ar.krakow.pl
}

Received: 06 June, 2006; revised: 31 August, 2006; accepted: 12 September, 2006 available on-line: 01 October, 2006

\begin{abstract}
A yeast isolate revealing unique enzymatic activities and substrate-dependent polymorphism was obtained from autochthonous microflora of soil heavily polluted with oily slurries. By means of standard yeast identification procedures the strain was identified as Trichosporon cutaneum. Further molecular PCR product analyses of ribosomal DNA confirmed the identity of the isolate with the genus Trichosporon. As it grew on methanol as a sole carbon source, the strain appeared to be methylotrophic. Furthermore, it was also able to utilize formaldehyde. A multi-substrate growth potential was shown with several other carbon sources: glucose, glycerol, ethanol as well as petroleum derivatives and phenol. Optimum growth temperature was determined at $25^{\circ} \mathrm{C}$, and strong inhibition of growth at $37^{\circ} \mathrm{C}$ together with the original soil habitat indicated lack of pathogenicity in warm-blooded animals and humans. The unusually high tolerance to xenobiotics such as diesel oil (>30 g/l), methanol $(50 \mathrm{~g} / \mathrm{l})$, phenol $(2 \mathrm{~g} / \mathrm{l})$ and formaldehyde $(7.5 \mathrm{~g} / 1)$ proved that the isolate was an extremophilic organism. With high-density cultures, formaldehyde was totally removed at initial concentrations up to $7.5 \mathrm{~g} / 1$ within $24 \mathrm{~h}$, which is the highest biodegradation capability ever reported. Partial biodegradation of methanol (13 g/l) and diesel fuel (20 g/l) was also observed. Enzymatic studies revealed atypical methylotrophic pathway reactions, lacking alcohol oxidase, as compared with the conventional methylotroph Hansenula polymorpha. However, the activities of glutathione-dependent formaldehyde dehydrogenase, formaldehyde reductase, formate dehydrogenase and unspecific aldehyde dehydrogenase(s) were present. An additional glutathione-dependent aldehyde dehydrogenase activity was also detected. Metabolic and biochemical characteristics of the isolated yeast open up new possibilities for environmental biotechnology. Some potential applications in soil bioremediation and wastewater decontamination are discussed.
\end{abstract}

Keywords: methylotrophic yeast, autochthonous microflora, Trichosporon sp., non-conventional yeast, xenobiotic biodegradation, formaldehyde

\section{INTRODUCTION}

The use of non-conventional yeasts in biotechnology has attracted much interest in recent years (Spencer et al., 2002). In environmental biotechnology, genera such as Pichia, Hansenula, Candida, Yarrowia, and Trichosporon are of special importance.
Among these, several species have been applied for recultivation of polluted soil, bioremediation of heavy metal contamination, treatment of industry-generated wastewaters, and used as microbiological sensors (Walker 1998; Spencer et al., 2002). Many useful strains for environmental projects have been isolated from natural habitats (water and soil),

^The paper was presented at XXXIII Winter School of Biotechnology „Various Faces of Biotechnology” organized by the Faculty of Biochemistry, Biophysics and Biotechnology Jagiellonian University, 25th February-2nd March 2006, Krynica, Poland.

Abbreviations: AldD, aldehyde dehydrogenase; AO, alcohol oxidase; FDD, formaldehyde dehydrogenase; Fd, formaldehyde; FDR, formaldehyde reductase; FMD, formate dehydrogenase; ITS, internal transcribed spacer. 
or from polluted areas (slurries and wastewaters) (Spencer et al., 2002). The application potential of these strains is often a result of rare enzymatic activities which enable them to gain resistance to toxic agents, to biodegrade certain xenobiotics, to produce specific metabolites, to detoxify detrimental metal compounds, etc.

Within the genus Trichosporon, over thirty species have been identified so far (Fell et al., 2000; Sugita et al., 2002; Middelhoven et al., 2004). Since the yeast is distributed in the environment very widely, the strains have been isolated from a variety of sources (Middelhoven et al., 2004), including plant and animal material, human clinical patients, air, water, industrial effluents, and preferably - soil (Middelhoven et al., 2001). Six to eight species have been reported to be medically important as disease-causing pathogens (Sugita et al., 1999; 2001; Middelhoven et al., 2001; Schwartz, 2004). Characteristics of the other ones proved that the genus comprises robust yeasts with a wide variety of biochemical pathways. Trichosporon species were reported to utilize benzene, phenol, and many other low-molecular weight aromatics (Middelhoven et al., 2004; Sampaio, 1999), biarylic compounds (Sietman et al., 2002), polycyclic aromatic hydrocarbons (MacGillivray et al., 1993), as well as other organic compounds, some of which are toxic (Sampaio 1999; Godjevargova et al., 2003; Middelhoven et al., 2004). However, there are only few reports on methanol assimilation capability (Aleksieva et al., 2002; Godjevargova et al., 2003) and formaldehyde biodegradation activity (Kato et al., 1982; Glancer-Soljan et al., 2001), revealed only by single strains of $T$. cutaneum and T. pennicilatum, respectively.

The described metabolic potential of Trichosporon species has made the application of these yeasts for environmental purposes very promising. Up to now, they have been used to treat industrial wastewater (Glancer-Soljan et al., 2001; Godjevargova et al., 2003) and applied as biosensors for determination of biological oxygen demand (BOD) (Yang et al., 1996), ammonium ion and phenol (Reiser et al., 1994). This paper describes a novel environmental yeast isolate of the genus Trichosporon. The unique biochemical and physiological features exhibited by this strain make it a microorganism of special biotechnological value.

\section{MATERIALS AND METHODS}

Strain identification methods. The isolated yeast was first identified by means of standard microbiological methods (Kurtzman, 2000) based on: (a) morphological features such as characteris- tics of growth in minimal rice medium, in which the tendency to form pseudomycelium and to produce chlamydospores and arthrospores was established, and (b) biochemical characteristics like carbohydrate fermentation capabilities as well as auxanography - assimilation of carbohydrate and nitrogen compounds.

Rapid molecular identification by means of PCR product analyses. Two independent molecular identification methods were performed: (a) amplification of a $170 \mathrm{bp}$ region of small-subunit (SSU) rDNA, according to Sugita et al. (1998), and (b) amplification of the conserved regions of 18S, 5.8S, and $28 \mathrm{~S}$ rDNA, according to Fujita et al. (2001). Several strains of the genus Candida served as negative controls.

DNA isolation and PCR amplification. Yeast strains were grown on $20 \mathrm{~g} / \mathrm{l}$ glucose in optimal medium for $24 \mathrm{~h}$ at $25^{\circ} \mathrm{C}$ (for other growth conditions see the next section). After centrifugation of a $15 \mathrm{ml}$ culture $\left(4800 \times \mathrm{g}, 10 \mathrm{~min}, 4^{\circ} \mathrm{C}\right)$, the cell pellets were kept frozen at $-80^{\circ} \mathrm{C}$, then re-suspended in $500 \mu \mathrm{l}$ of STET buffer and homogenized with $200 \mu \mathrm{l}$ of $0.5 \mathrm{~mm}$ glass beads by vigorous vortexing for $8 \mathrm{~min}$., and boiling in a water bath for $3 \mathrm{~min}$. After cooling on ice the samples were centrifuged $(28000 \times g$ for 10 $\min$ at $4^{\circ} \mathrm{C}$ ) and then to $300 \mu \mathrm{l}$ of each supernatant, $700 \mu \mathrm{l}$ of $7.5 \mathrm{M}$ ammonium sulfate was added, incubated overnight at $-20^{\circ} \mathrm{C}$, and centrifuged as above. DNA was precipitated from supernatants with $96 \%$ ethanol. After centrifugation, the pellets were dried and dissolved in $50 \mu \mathrm{l}$ of water. DNA was purified with the Wizard SV gel and PCR clean-up system (Promega).

For the amplification of a $170 \mathrm{bp}$ region of small-subunit rDNA the following primers were used: TRF (5'-AGAGGCCTACCATGGTATC-3') and TRR (5'-TAAGACCCAATAGAGCCCTA-3') (Sugita et al., 1998). For the amplification of ITS1 and ITS2 regions and the region of $5.8 \mathrm{~S}$ rDNA the primers used were: C_ITS1_F (5'-TCCGTAGGTGAACCTGCG-3'), C_ITS3_F (5'-GCGTCGATGAAGAACGCAGC-3'), and C_ITS4_R (5'-TCCTCCGCTTATTGATATGC-3'). All primers were obtained from Generi Biotech (Czech Republic).

The amplification was done in a Mastercycler gradient thermocycler (Eppendorf). Total reaction volume was $15 \mu \mathrm{l}$, of which the master mixture was composed of $5 \mathrm{mM} \mathrm{MgCl}$ (Qiagen), 1× buffer (Qiagen PCR Buffer), $0.25 \mathrm{mM}$ dNTP mix (Fermentas), $0.25 \mu \mathrm{M}$ of each primer pair, $0.075 \mathrm{U}$ HotStraTaq Polymerase (Qiagen), $1.5 \mu \mathrm{l}$ of DNA, and distilled water. Reaction conditions consisted of an initial step of $15 \mathrm{~min}$ at $5^{\circ} \mathrm{C}$ and 35 cycles of subsequent steps: (a) $92^{\circ} \mathrm{C}$ for $45 \mathrm{~s}$, (b) $57^{\circ} \mathrm{C}$ for $45 \mathrm{~s}$, and (c) $72^{\circ} \mathrm{C}$ for 2 min. The ending elongation was carried out at $72^{\circ} \mathrm{C}$ for $10 \mathrm{~min}$. 
Yeast cell cultures. Yeasts were grown either in optimal or minimal media containing $2 \%$ $(\mathrm{v} / \mathrm{v})$ (that is $1.58 \mathrm{~g} / \mathrm{l})$ methanol or other xenobiotics at desired concentrations, in $300 \mathrm{ml}$ Erlenmeyer flasks in thermostated gyro-shakers (200 r.p.m., at $25^{\circ} \mathrm{C}$ ). Optimal growth medium contained (per liter): $3 \mathrm{~g}\left(\mathrm{NH}_{4}\right)_{2} \mathrm{SO}_{4^{\prime}} 0.5 \mathrm{~g} \mathrm{KH}_{2} \mathrm{PO}_{4^{\prime}} 0.3 \mathrm{~g} \mathrm{MgSO}_{4} \times$ $7 \mathrm{H}_{2} \mathrm{O}, 0.2 \mathrm{~g} \mathrm{CaCI}_{2} \times 6 \mathrm{H}_{2} \mathrm{O}, 2 \mathrm{~g}$ yeast extract, and 2 $\mathrm{g}$ peptone. Minimal medium contained salt solutions as above, and $0.2 \mathrm{~g} / 1$ yeast extract. To this medium $0.5 \mathrm{ml} / \mathrm{l}$ of microelement cocktail $\left(\mathrm{H}_{3} \mathrm{BO}_{3}, 56 \mathrm{mg} / \mathrm{l}\right.$; $\mathrm{CuSO}_{4} \times 5 \mathrm{H}_{2} \mathrm{O}, 39.3 \mathrm{mg} / \mathrm{l} ; \mathrm{MnSO}_{4} \times 7 \mathrm{H}_{2} \mathrm{O}, 50.4 \mathrm{mg} /$ l; $\left(\mathrm{NH}_{4}\right)_{6} \mathrm{Mo}_{7} \mathrm{O}_{24} \times \mathrm{H}_{2} \mathrm{O}, 120 \mathrm{mg} / \mathrm{l} ; \mathrm{ZnSO}_{4} \times 7 \mathrm{H}_{2} \mathrm{O}$, $307.9 \mathrm{mg} / \mathrm{l})$ was added. Iron $(0.2 \mathrm{mg} / \mathrm{l})$ was provided with Mohr salts.

Solid YPD media for yeast culture plating contained $20 \mathrm{~g} / \mathrm{l}$ peptone, $10 \mathrm{~g} / \mathrm{l}$ yeast extract, $20 \mathrm{~g} / 1$ glucose and $20 \mathrm{~g} / \mathrm{l}$ bacto-agar. Sabouraud agar with an appropriate antibiotic cocktail (see Results and Discussion) was used for yeast selection.

Biomass density was evaluated turbidimetrically, as optical density at $540 \mathrm{~nm}\left(\mathrm{OD}_{540}\right)$. It was checked experimentally that $\mathrm{OD}_{540}=1.0$ corresponded to approx. $1.9 \times 10^{7}$ cells $/ \mathrm{ml}$. Cell culture viability was verified by plating appropriate culture decimal dilutions onto solid agar media and then by counting c.f.u. The methylotrophic yeast Hansenula polymorpha NCYC 2309 was used as a reference strain in the experiments.

Yeast growth and xenobiotic biodegradation tests. For growth tests, Trichosporon sp. was inoculated at a low density $\left(\mathrm{OD}_{540}=0.01\right.$, that is $1.9 \times$ $10^{5}$ cells $/ \mathrm{ml}$ ) to media supplemented with particular sources of carbon.

In biodegradation experiments, high density Trichosporon sp. cultures (typically of $\mathrm{OD}_{540}=1.2$, corresponding to $2.3 \times 10^{7}$ cells $/ \mathrm{ml}$ ), pre-grown on 20 $\mathrm{ml} / \mathrm{l}$ methanol up to the logarithmic growth phase, were centrifuged $(3000 \times g$ for $5 \mathrm{~min}$ ) to remove the optimal medium and then the cells were re-suspended in media containing different xenobiotics.

Preparation of cellular extracts. Yeast cell cultures were centrifuged $(3000 \times g$ for $5 \mathrm{~min})$ to remove the medium, then to each $1 \mathrm{~g}$ of the cellular pellet $1 \mathrm{ml}$ buffer ( $25 \mathrm{mM}$ Tris/ $\mathrm{HCl}, \mathrm{pH}$ 7.5, containing 50 $\mathrm{mM}$ EDTA and 10\% dithiothreitol) was added. The tube with cell suspension was cooled by placing in an ice bath and then the cells were disrupted in four 15 min cycles with a laboratory sonicator UP $50 \mathrm{H}$ Ultrasonic Processor (dr. Hielscher $\mathrm{GmbH}$ ) using an MS7 sonotrode (50\% maximum output power, $0.5 \mathrm{~s}$ pulses).

Protein profiles of cellular extracts were obtained using polyacrylamide gel electrophoresis in the presence of sodium dodecyl sulfate (SDS/PAGE), according to Laemmli (1970). Gels were stained with Coomassie Brilliant Blue R-250, and protein determi- nation in cellular extracts was done according to the method of Lowry et al. (1951).

Determination of enzyme activities in kinetic tests. The activities of glutathione-dependent formaldehyde and aldehyde dehydrogenases in cellular yeast extracts were measured by means of spectrophotometric determination of the generated $\mathrm{NADH}$ at $\lambda=340 \mathrm{~nm}$ (Jasco V-530 UV/VIS spectrophotometer). The reaction mix consisted of $0.6 \mathrm{mM}$ $\mathrm{NAD}^{+}, 0.1 \mathrm{mM}$ glutathione (GSH), $5 \mathrm{mM} \mathrm{KCl}$, and $10 \mathrm{mM}$ formaldehyde or acetaldehyde as substrates. Yeast alcohol dehydrogenase and aldehyde dehydrogenase were used as reference controls. In brief, $1 \mathrm{ml}$ of the reaction mix was placed in a standard quartz cuvette and then $0.3 \mathrm{ml}$ of the tested extract was added to start the enzymatic reaction.

Zymographic analyses of the extracts were performed to reveal activities of unspecific aldehyde dehydrogenases. The reagent solution for native PAGE enzymatic staining contained $25 \mathrm{mg}$ of $\mathrm{NAD}^{+}$, $15 \mathrm{mg}$ of $p$-nitroblue tetrazolium chloride (NBT), 1 $\mathrm{mg}$ of phenazine methosulfate (PMS), $10 \mathrm{ml}$ of $0.2 \mathrm{M}$ Tris/HCl, $\mathrm{pH} 7.5,1 \mathrm{ml}$ of $50 \mathrm{mM} \mathrm{KCl}, 35 \mathrm{ml}$ of water, $1 \mathrm{ml}$ of $10 \mathrm{mM}$ cysteine as a donor of thiol groups, and $5 \mathrm{ml}$ of $1 \mathrm{M}$ acetaldehyde as a substrate.

All chemicals used were of analytical grade. The solutions and buffers were made using bidistilled water, and whenever required, fully sterile conditions were applied.

Analytical methods. Methanol and diesel-fuel constituents were determined by a gas chromatography analysis using Schimadzu GC- 17A ver. 3 gas chromatograph equipped with a capillary column Zebron ZB-5 (Phenomenex) $30 \mathrm{~m} / \varnothing 0.32$ filled with $5 \%$ Phenyl Polysiloxane. A flame ionization detector (FID) was used. Temperature gradients were optimized for the compounds to be determined.

Formaldehyde concentration was determined by means of Nash reagent (Nash, 1953), as described earlier (Kaszycki \& Koloczek, 2000).

\section{RESULTS AND DISCUSSION}

\section{Isolation of the strain}

The yeast strain was isolated from autochthonous microflora present in oil slurry-contaminated soil in a petroleum-refinery industrial area in southern Poland. An approx. $10 \mathrm{~g}$ sample of polluted soil was suspended in $90 \mathrm{ml}$ of distilled sterile water and incubated for $3 \mathrm{~h}$ at room temperature in 500 $\mathrm{ml}$ flasks shaken in a laboratory rotary shaker (200 r.p.m.). Then the soil, sand and other solid particles were filtered out and the remaining suspension was enriched with a minimum amount of bacto-peptone 
and yeast extract $(0.5 \mathrm{~g} / \mathrm{l}$ each) and treated with gradually increasing amounts of the original soil organic extract. This procedure enabled over several weeks the development of a consortium of microbial species capable of utilizing xenobiotics present in the soil. The obtained biocenosis consisted of several bacterial and yeast species. To isolate yeast, appropriate dilutions of the original suspension were spread onto Petri dishes with solid Sabouraud medium. After growth at $30^{\circ} \mathrm{C}$ for 2 days single colonies were picked based on their morphology and microscopic observations and re-plated onto solid media containing an antibiotic cocktail $(40 \mathrm{mg} / \mathrm{l}$ streptomycin, $28 \mathrm{mg} / \mathrm{l}$ penicillin). The isolated yeast strains were tested for assimilation of xenobiotics, and one isolate that tended to form pseudomycelium was selected for the current study. The strain was then stored on solid beer-agar slants.

\section{Description and identification of the yeast isolate}

Optimal conditions for growth were determined. The cultures grew well under aerobic conditions, with aeration provided by vigorous rotaryshaking culture flasks (200 r.p.m.), at an optimal temperature between 25 and $26^{\circ} \mathrm{C}$. The $\mathrm{pH}$ value of 8.1-8.2 was found to be physiological, and it was spontaneously maintained by the growing yeast, both on glucose and on methanol. The growth of the isolated Trichosporon sp. was strongly inhibited at temperatures above $30^{\circ} \mathrm{C}$, which is an important feature that reduces any risk of pathogenicity for animals and humans.

Cells grown on solid Sabouraud medium after 5-day growth at $25^{\circ} \mathrm{C}$ formed slant, textured, creamy-coloured shiny colonies, as presented in Fig. 1a. During prolonged incubation (up to 3 weeks, Fig. 1b) the culture evolved into yellowish wrinkled pseudomycelium, elevated at the bottom and forming fimbriate-like margins. Three-day cultures (Fig. 1c) grown at $25^{\circ} \mathrm{C}$ in the liquid optimal medium containing $2 \%$ glucose, revealed relatively large, oval (approx. $5 \mu \mathrm{m}$ diameter), ellipsoidal or elongate shapes (up to $15 \mu \mathrm{m}$ ), appearing as single cells or forming pairs and chain-like or branched aggregates. Budding was often visible.

The isolated yeast was multi-trophic as it was able to grow in minimal media containing either one of several organic compounds as sole carbon sources: methanol, ethanol, glycerol, diesel oil, all at the tested concentrations of $20 \mathrm{~g} / \mathrm{l}$, and phenol at $1.5 \mathrm{~g} / \mathrm{l}$. Cell culture appearance in liquid media varied depending on the carbon source, revealing an unusual substrate-based polymorphism (Fig. 1d-h).

The yeast was identified by means of the standard microbiological method (Kurtzman, 2000) in which the cell morphology, colony appearance, pseudo-true hyphae formation, substrate assimilation, physiological characteristics, and biochemical activities were considered. Such a phenotypic screening resulted in the species Trichosporon cutaneum (Basidiomycota, Hymenomycetes, Tremelloidae, Trichosporonales). However, several unique physiological attributes that seem to be characteristic of the novel strain suggested the need of a more thorough identification approach. Therefore, we performed PCRbased analyses of ribosomal DNA with two independent methods, both of which had been used for identification of Trichosporonales (Sugita et al., 1998; Fujita et al., 2001).

Both molecular analyses suggested the genus to be Trichosporon; however, the species identity could not be established at this level. It can be observed in Fig. 2 lane $c$ that the first analysis revealed the amplification of a $170 \mathrm{bp}$ region of small-subunit rDNA which served as a molecular marker for the genus. The negative result (Fig. 2 lanes a and b) obtained from the reference strain Candida sp. confirmed our conclusion. In the second test, as presented in Fig. 3, the primers ITS1-ITS4 were used to amplify the conserved regions of $18 \mathrm{~S}$, $5.8 \mathrm{~S}$, and $28 \mathrm{~S}$ rDNA, and the ITS3 and ITS4 primer pair was used to amplify the $5.8 \mathrm{~S}$ rDNA region and the adjacent ITS2 region. As seen in Fig. 3 A and B, the respective lanes $\mathrm{d}$ show the amplified products of approx. 530 and $350 \mathrm{bp}$, which match very well the expected range of ITS1-ITS4 (522, 536, $539 \mathrm{bp})$ and ITS3-ITS4 (349, 356, 354 bp), from which Fujita et al. (2001) were able to identify three Trichosporon species. Again, the negative controls obtained for three Candida strains supported the reliability of the analysis.

It should be noted here that the precise identification of basidiomycetous yeasts is very difficult, even with the use of combined standard and molecular techniques, as pointed out by Fell et al. (2000). Thus, our isolate still requires a non-traditional approach for definite species identification, which was also postulated for Trichosporon environmental isolates by Middelhoven et al. (2004).

\section{Tolerance for selected xenobiotics}

High density Trichosporon sp. cultures, pregrown on $20 \mathrm{ml} / \mathrm{l}$ methanol up to the logarithmic growth phase $\left(\mathrm{OD}_{540}\right.$ within the range 1.2-2.0), were re-suspended in media containing different concentrations of methanol, phenol, diesel fuel, or formaldehyde. Cell culture viability was checked for 36 $\mathrm{h}$ by culture plating at 12 -h time intervals. All the tested xenobiotics were found not to affect the cell survival at the concentrations applied up to $50 \mathrm{~g} /$ l, $2 \mathrm{~g} / \mathrm{l}, 30 \mathrm{~g} / \mathrm{l}$ (the highest tested), and $1.2 \mathrm{~g} / \mathrm{l}$, respectively. Methanol at $100 \mathrm{~g} / \mathrm{l}$ led to a drop of cell 

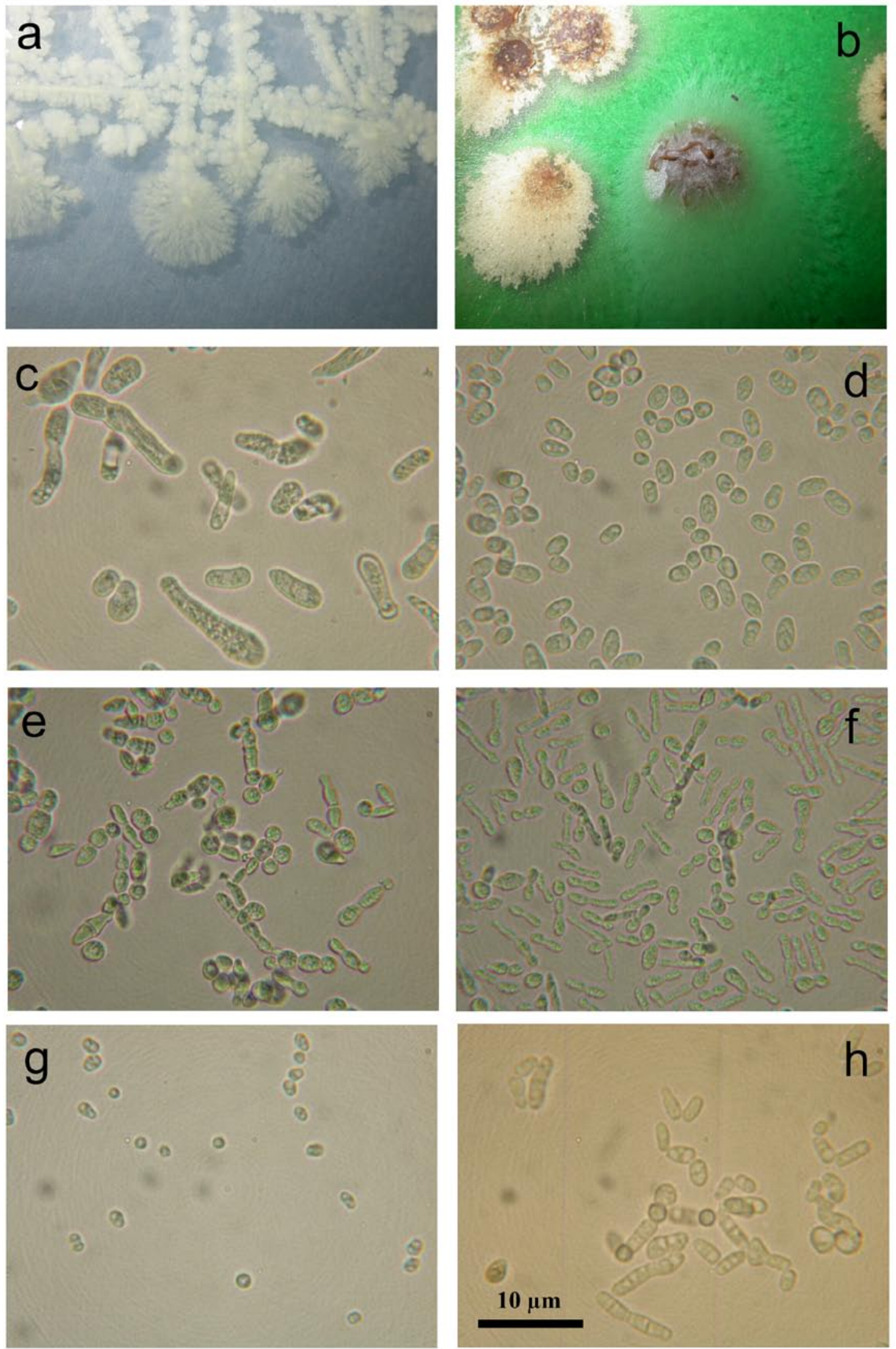

Figure 1. (a), (b) Macro-photographic morphology of colonies formed by Trichosporon sp. isolate on agar plates after 5-day (a) and 2-week (b) incubation; (c)-(h) Microscopic (magnification $600 \times$ ) images of substrate-dependent 3-day cell culture polymorphism in liquid minimal media with glucose (c), methanol (d), ethanol (e), glycerol (f), diesel fuel $(\mathrm{g})$, and phenol $(\mathrm{h})$ as sole carbon sources. Growth substrates were applied at $20 \mathrm{~g} / \mathrm{l}$, except for phenol (1.5 g/l). 


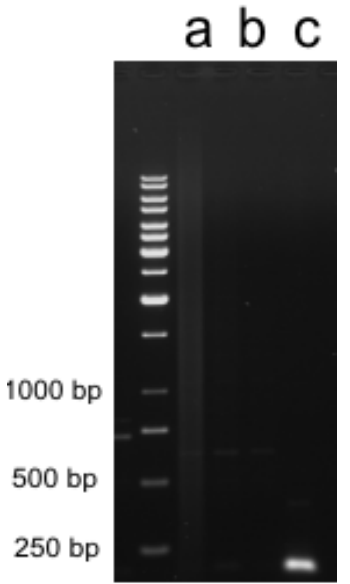

Figure 2. Molecular identification of the genus Trichosporon based on the amplification of a $170 \mathrm{bp}$ region of smallsubunit (SSU) rDNA, according to the method of Sugita et al. (1998).

Lanes (a) and (b), negative controls (genus: Candida); lane (c), the tested strain isolate - a positive result is represented by the amplified product of $170 \mathrm{bp}$.

survival by $74 \%$, and $2.5 \mathrm{~g} / \mathrm{l}$ phenol caused a $38 \%$ viability decrease.

The described high tolerance to phenol (above $2000 \mathrm{mg} / \mathrm{l}$ ) placed the yeast among one of the microorganisms most resistant to this compound (Tsai et al., 2005; Dzirba et al., 2006). For the highly tolerant yeast Candida albicans TL3, Tsai et al. (2005) reported the culture growth capability at a phenol concentration up to $24 \mathrm{mM}$ (approx. $2250 \mathrm{mg} / \mathrm{l}$ ). Within the genus Trichosporon, however, the highest reported phenol resistance $(1700 \mathrm{mg} / \mathrm{l})$ was found for T. cutaneum (Santos \& Linardi, 2001).

Formaldehyde ( $\mathrm{Fd})$ as a single xenobiotic in the medium proved to be lethal at concentrations above $0.2 \%(2000 \mathrm{mg} / \mathrm{l})$. The observed tolerance is very high since $\mathrm{Fd}$ is an extremely toxic agent

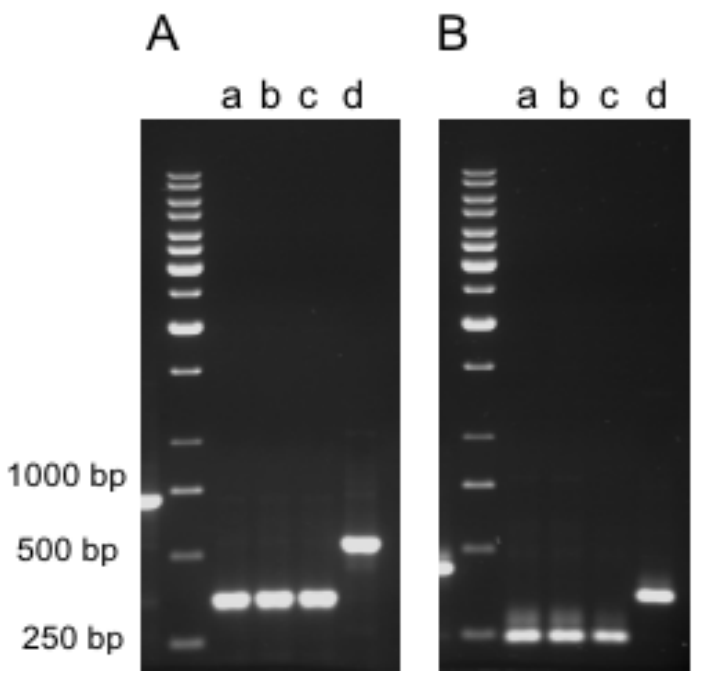

Figure 3. Molecular identification of the genus Trichosporon based on the amplification of the conserved regions of 18S, 5.8S, and $28 \mathrm{~S}$ rDNA, following the method of Fujita et al. (2001).

PCR amplification products were obtained for the primers (A) ITS1-ITS4 and (B) ITS3-ITS4. Respective lanes (a)-(c), negative controls (genus: Candida); lanes (d), the tested strain isolate - a positive result is represented by the amplified product of $530 \mathrm{bp}$ and $350 \mathrm{bp}$ for (A) and (B), respectively.
(Bardana \& Montanaro, 1991; Gonzalez-Gil et al., 2000). Fd presence negatively affects various microorganisms at much lower concentrations, and at levels above $1000 \mathrm{mg} / \mathrm{l}$ it cannot be tolerated even by most of preadapted biocenoses such as activated sludges (Qu \& Bhattacharya, 1997; Gonzalez-Gil et al., 2000). However, with our Trichosporon isolate, an even more striking result was obtained when $1.58 \mathrm{~g} /$ $1(2 \%, v / v)$ methanol was added to the culture medium. The high density culture of the yeast gained tolerance up to $7500 \mathrm{mg} / \mathrm{l}$ of formaldehyde. To our knowledge, this is the first report of a microorganism exhibiting such a resistance to formaldehyde, which, together with the observed high survival in the presence of other xenobiotics makes it reasonable to consider the strain as extremophilic (Satyanarayana et al., 2005). As the Fd resistance was due to an enhanced ability to biodegrade this compound, detailed data and further discussion are given in the biodegradation section below.

\section{Biodegradation potential}

The strain was tested for biodegradation efficiency of xenobiotics such as diesel oil, methanol and formaldehyde. As described above, high-density cell suspensions were used $\left(\mathrm{OD}_{540}=1.2\right.$, which corresponded to $2.3 \times 10^{7}$ cells $/ \mathrm{ml}$ ).

In the case of diesel fuel, which consists of a number of aliphatic and aromatic hydrocarbons, the biodegradation was gradual over time and led to a decrease of the total amount of the initial xenobiotic load $(20 \mathrm{~g} / \mathrm{l})$ by approx. 50\% within 11 days of the test. The initial and final stages of the experiment are shown in Fig. 4, where gas-chromatographic analyses revealed the concomitant degradation of practically all the constituents detected. The obtained biodegradation efficiency was lower than that observed for specialized bacterial consortia (Hamme et al., 2003); however, it was comparable to the results obtained for monocultures of other autochthonous yeasts isolated from oil-contaminated soil (Koloczek et al., 2004). The ability of the Trichosporon $\mathrm{sp}$. isolate to utilize complex hydrocarbon mixtures indicated the presence of a rich enzymatic apparatus responsible for the metabolism of a variety of organic compounds.

Methanol was not removed from the medium completely, regardless of the initial concentration applied. This rather surprising result was not caused by any decrease in the culture viability. As presented in Fig. 5, although the initial level was not lethal to the yeast $(13000 \mathrm{mg} / \mathrm{l})$, methanol decreased within 8 days over two-fold; past this time, its concentration remained constant. The mechanism of the partial degradation of methanol requires further studies, especially with growing, methanol-limited cultures. It 


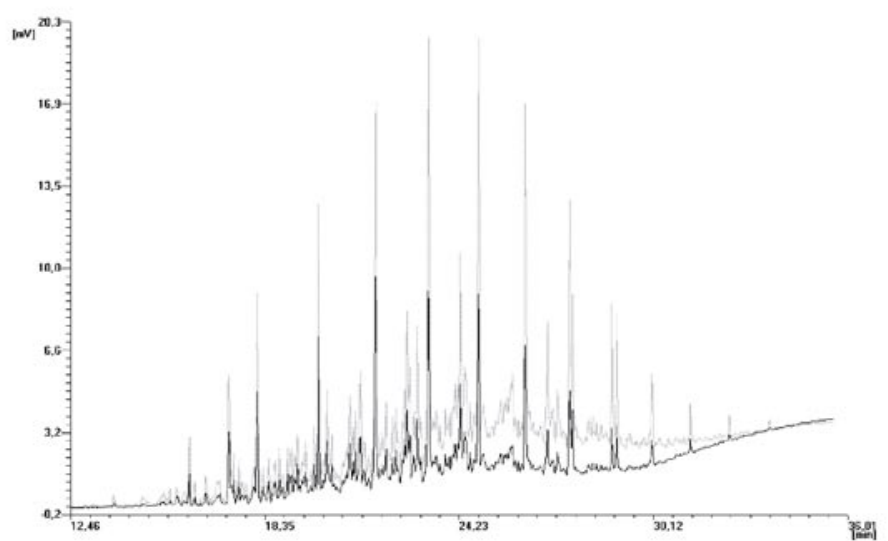

Figure 4. Gas-chromatography analysis of the degradation of diesel oil by Trichosporon sp. high-density culture.

Gray line, start of the process; black line, after 11 days. should be pointed out here that other methanol-assimilating yeasts are capable of totally reducing the level of this compound (Kaszycki \& Koloczek, 2000; Kaszycki et al., 2001).

The formaldehyde biodegradation kinetics obtained with the isolated strain is shown in Fig. 6 . The dotted and solid lines represent maximum levels of Fd utilized under two experimental conditions studied: in the absence of methanol and in a mixture with $1.58 \mathrm{~g} / 1$ methanol, respectively. As mentioned earlier, the strain tolerance toward formaldehyde was achieved by means of its effective metabolic removal, which is in agreement with our previous experiments with the methylotrophic model yeast Hansenula polymorpha (Kaszycki et al., 2001). The presence of methanol enhanced the ability to degrade Fd almost five-fold, by means of a mechanism which is yet to be explained. The possibility of co-metabolism of both substrates should be considered. A higher potential for Fd biodegradation in the presence of methanol has also been reported in other studies (Eiroa et al., 2004a; 2005a), including methylotrophic yeast (Kaszycki et al., 2001).

In our experiments we used several increasing $\mathrm{Fd}$ concentrations and the intriguing result was that the period of total degradation of formaldehyde never exceeded $24 \mathrm{~h}$. The lack of a direct correlation of the biodegradation time with the concentration

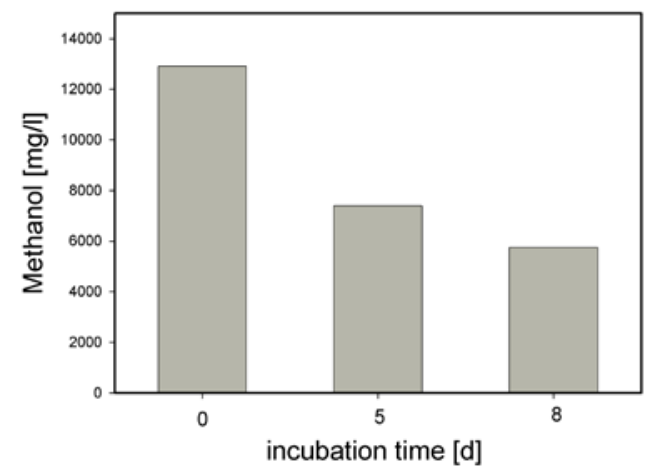

Figure 5. Degradation of methanol by Trichosporon sp. high-density culture $\left(2.3 \times 10^{7}\right.$ cells $\left./ \mathrm{ml}\right)$. of formaldehyde applied was in contrast to the case of H. polymorpha (Kaszycki et al., 2001), where such a dependence was straightforward. Also, unlike H. polymorpha, before treatment with sub-lethal $\mathrm{Fd}$ levels, Trichosporon sp. required no pre-cultivation with smaller doses of the xenobiotic.

Another important observation was that the isolated Trichosporon sp. could not grow on formaldehyde as a sole carbon source (not shown), although it was able to metabolize high doses of this xenobiotic. This, again, is in opposition to our results obtained for $H$. polymorpha which proved to gain biomass upon Fd assimilation (Kaszycki \& Koloczek, 2000).

The described physiological differences between Trichosporon sp. and other methylotrophic strains might suggest the presence of diverse enzymatic mechanisms (see below).

On the other hand, upon Fd biodegradation, the studied yeast isolate tended to acidify the incubation medium from the initial value of $\mathrm{pH} 8.1$ to a $\mathrm{pH}$ below 6.0, as shown in the lower section of Fig. 6. It was a very efficient process (a drop of $\mathrm{pH}$ was observed in a matter of seconds) and could be explained by the action of formate dehydrogenase (FMD, EC 1.2.1.2). This enzyme has been found in methylotrophic yeasts, and the culture medium acidification during Fd degradation was found to be similar (Maidan et al., 1997, and our observations, not shown).

The maximum biodegradation efficiency $(7500$ $\mathrm{mg} / \mathrm{l}$ consumed within $24 \mathrm{~h}$ ) revealed by the Trichosporon isolate and reported in this study is exceptionally high and has never been observed for any aerobic or anaerobic organism, microbial consortia or activated sludge.

Among Trichosporonales, only $T$. penicillatum was able to oxidize formaldehyde (Kato et al., 1982), and this species was used to treat industrial wastewater with an $\mathrm{Fd}$ concentratrion of $1000 \mathrm{mg} / \mathrm{l}$ (Glancer-Soljan et al., 2001). Our previous research on methylotrophic yeast (Kaszycki et al., 2001) proved that preadapted $H$. polymorpha culture was capable of biodegrading formaldehyde at concentrations up 


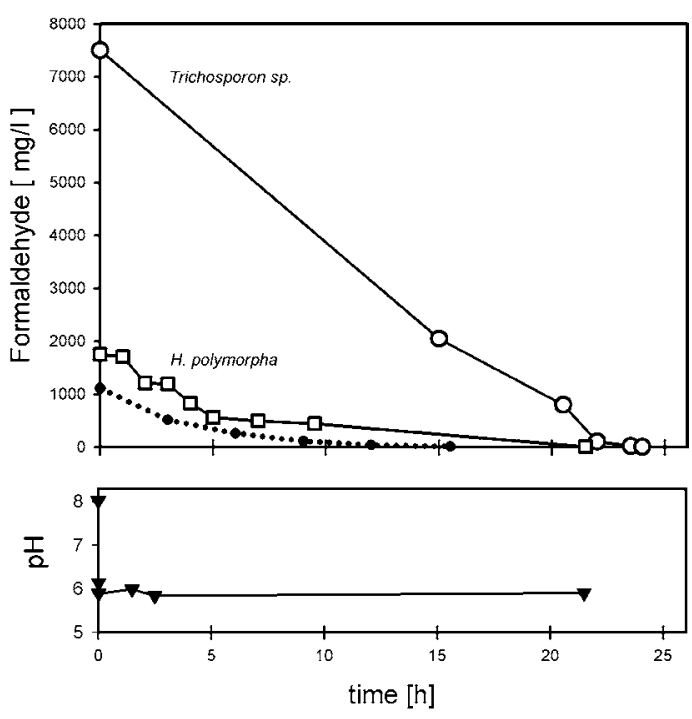

Figure 6. Biodegradation of formaldehyde.

Upper section: maximum Fd levels biodegraded with Trichosporon sp. (circles) and with Hansenula polymorpha (squares) in the presence of methanol $(1.58 \mathrm{~g} / \mathrm{l})$. The dotted line represents maximum $\mathrm{Fd}$ biodegradation potential of Trichosporon sp. in the absence of methanol. Lower section: $\mathrm{pH}$ value of Trichosporon sp. culture medium during $\mathrm{Fd}$ biodegradation in the presence of methanol.

to $1750 \mathrm{mg} / 1$ (Fig. 6, squares). Recently, Mirdamadi et al. (2005) reported an aerobic bacterial strain of Pseudomonas pseudoalcaligenes that consumed 3700 $\mathrm{mg} / \mathrm{l}$ of formaldehyde within $24 \mathrm{~h}$. Extreme concentrations of formaldehyde were tested with sludges in wastewater-treatment model upflow reactors. The tests were performed under aerobic (up to $3168 \mathrm{mg} /$ 1 of $\mathrm{Fd}$, Eiroa et al., 2005b), anoxic (up to $5000 \mathrm{mg} / \mathrm{l}$, Eiroa et al., 2004a), and anaerobic conditions (1110 $\mathrm{mg} / \mathrm{l}, \mathrm{Qu} \&$ Bhattacharya, 1997), as well as in batch culture reactors (3890 mg/l, Eiroa et al., 2004a).

\section{Methylotrophy}

The ability to metabolize single-carbon compounds is essential for methylotrophy (Michalik, 1975; Michalik \& Raczynska-Bojanowska, 1976; Gleeson \& Sudbery, 1988; Sibirny et al., 1988). The isolate of study showed its ability to assimilate methanol

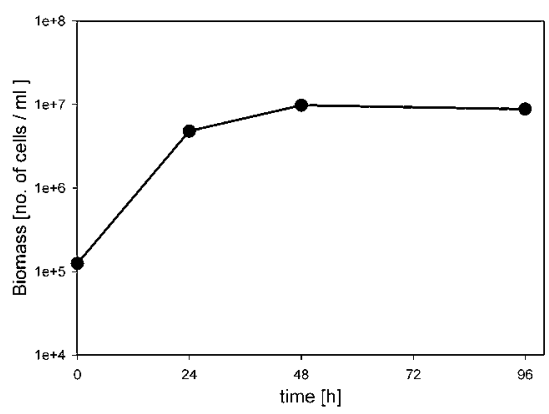

Figure 7. Growth kinetics of Trichosporon sp. culture on methanol $(1.58 \mathrm{~g} / \mathrm{l})$ as a sole carbon source. and to utilize formaldehyde, proving to be a methylotrophic yeast. The growth of the Trichosporon sp. isolate can be observed in Fig. 7. The liquid optimal medium containing $2 \%(\mathrm{v} / \mathrm{v})$ methanol was inoculated with the yeast at a low density, i.e. at approx. $10^{5}$ cells $/ \mathrm{ml}$. Rapid growth was then observed, and the culture proliferated after a relatively short lag phase to gain the density of over $10^{7}$ cells $/ \mathrm{ml}$ within 2 days. Both the growth dynamics and the shape of the growth curve resembled that obtained for the methylotrophic yeast $H$. polymorpha (Sibirny et al., 1988; Kaszycki \& Koloczek, 2000).

\section{Preliminary enzymatic characteristics}

For the extraordinary biochemical features of the isolated Trichosporon sp. it was of interest to search for the enzymatic background determining the physiological activities. In a preliminary study, some of the enzyme activities characteristic of the methylotrophic pathway reactions were examined and compared with a model methylotrophic strain of Hansenula polymorpha (Gleeson \& Sudbery, 1988; Sibirny et al., 1988) for enzymatic characterization of the pathway.

SDS/PAGE electrophoresis performed for cellular extracts of methanol-grown cultures of $H$. polymorpha and Trichosporon sp. revealed that the newly isolated strain was lacking in the key enzyme of the conventional methylotrophic pathway - alcohol oxidase (AO, EC 1.1.3.13) (Fig. 8). Since this enzyme is responsible for methanol oxidation as the first step in assimilation reactions, the pathway for methanol utilization in Trichosporon sp. must be substantially different.

In order to reveal the activity of glutathionedependent formaldehyde dehydrogenase (FDD, EC 1.2.1.1), kinetic activity tests were performed using Trichosporon sp. crude cellular extracts. This enzyme is also typical for methylotrophic yeast and is claimed to be mainly responsible for the Fd-detoxifying action of the methylotrophic pathway. Fig. 9 (solid line) gives proof of the presence of a significant FDD activity, which was comparable to the

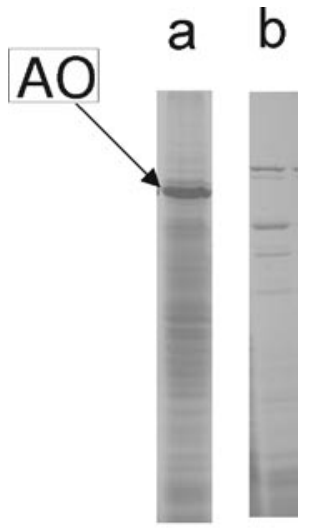

Figure 8. SDS/PAGE electrophoretic analysis of cellular extracts of the isolated strain Trichosporon sp. (lane b) as compared with Hansenula polymorpha (lane a).

The arrow points to the protein band of $64 \mathrm{kDa}$, indicating the presence of alcohol oxidase $(\mathrm{AO})$. 


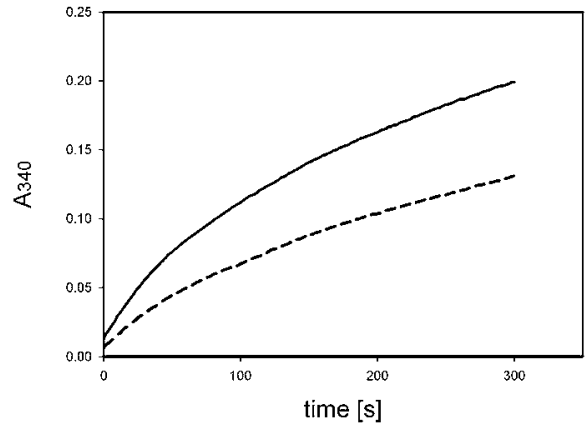

Figure 9. Demonstration of aldehyde dehydrogenase activities in cellular extracts of Trichosporon sp.

Solid line, glutathione-dependent formaldehyde dehydrogenase (FDD); dotted line, glutathione-dependent aldehyde dehydrogenase (AldD). To reveal activities of the two enzymes, formaldehyde and acetaldehyde were used as substrates, respectively.

activities obtained for $H$. polymorpha extracts (not shown). At the same time, by using glutathione and acetate aldehyde as substrates, a new activity of a glutathione-dependent aldehyde dehydrogenase was revealed (Fig. 9, dotted line). This interesting finding might indicate the existence of a novel, yet unidentified dehydrogenase. The observed activity was not due to FDD since the latter enzyme is substrate (i.e. formaldehyde) specific. Similar activity has never been detected in $H$. polymorpha.

Zymographic analyses were applied to check for the presence of unspecific aldehyde dehydrogenase (AldD, EC 1.2.1.5). Zymograms were obtained for Trichosporon sp. and H. polymorpha (Fig. 10b and a, respectively), revealing strong acetaldehyde-based activities for both strains, yet significant differences between the two lanes were visible. The pattern observed for the new Trichosporon isolate might suggest an involvement of different enzymatic proteins as compared to conventional methylotrophs. This constitutes a future case for detailed study since unspecific aldehyde dehydrogenases may play an important role in $\mathrm{Fd}$ dissimilation reactions, as pointed out by Maidan et al. (1997).

It would also be interesting to find out whether exogenous formaldehyde was reduced to methanol by the activity of NADH-dependent formaldehyde reductase, another enzyme that has

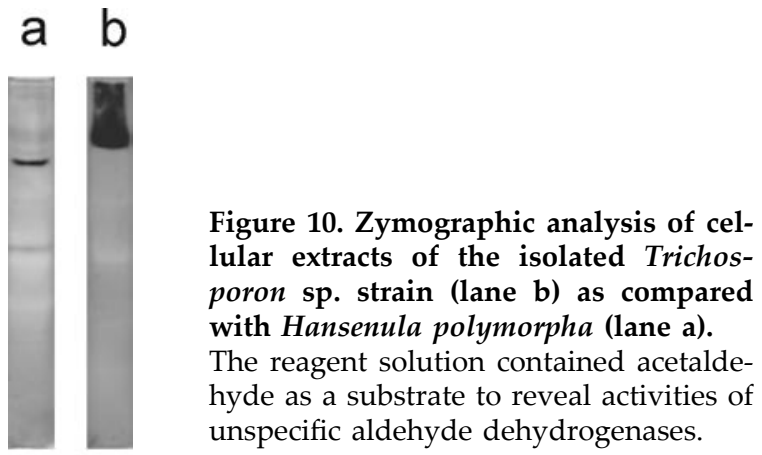

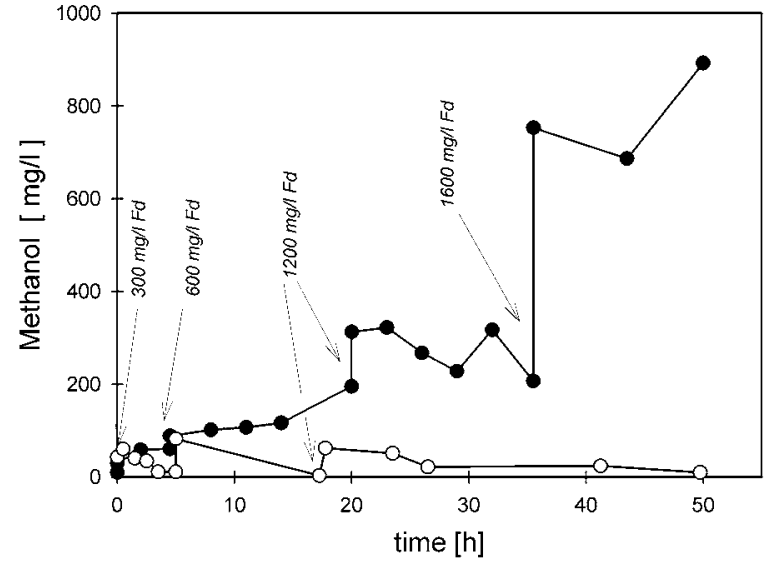

Figure 11. Generation of endogenous methanol upon formaldehyde biodegradation by the isolate Trichosporon sp. (solid circles) as compared with Hansenula polymorpha (open circles).

Subsequent doses of formaldehyde are indicated by arrows and they were added after total degradation of the preceding Fd portion.

been identified in methylotrophic yeasts. This is an NADH-dependent formaldehyde-reducing enzyme and might be important for $\mathrm{Fd}$ detoxification action as it generates the less toxic methanol. Indeed, when Trichosporon sp. culture was treated with increasing formaldehyde amounts, methanol was formed in a dose-dependent manner (Fig. 11, solid circles) and tended to cumulate in the medium (up to $900 \mathrm{mg} / \mathrm{l}$ in Fig. 11). This was unlike the test with $H$. polymorpha, where the endogenous Fd-generated pool of methanol was efficiently removed by methanol-utilizing enzymes (Fig. 11, open circles), never exceeding the level of $100 \mathrm{mg} / \mathrm{l}$.

Regarding the observed physiological reaction to the presence of formaldehyde with Trichosporon sp., it is difficult to account for the discrepant results which prove efficient methanol-based growth and its assimilation, on one hand, and endogenous methanol accumulation on the other. However, when the activities of $\mathrm{NAD}^{+}$-dependent $\mathrm{Fd}$ and aldehyde dehydrogenases were taken into account, the presence of a regulatory mechanism that triggers FDR might be suggested. Upon Fd administration the culture could react with an immediate dehydrogenase action, which would lead to the generation of excess $\mathrm{NADH}$ and to a deficit in the $\mathrm{NAD}^{+}$pool. Since it is known that NADH down-regulates FDD and FMD, the dissimilative $\mathrm{Fd}$ pathway would be inhibited whereas $\mathrm{NAD}^{+}$ could be regenerated by means of FDR activity. The proposed enzymatic interaction mechanism in Trichosporon sp. needs to be further verified and elucidated, however.

Summing up, the newly isolated strain of Trichosporon sp. reveals a methylotrophic biochemical pathway, several enzymes of which could be 
identified in a model methylotrophic yeast, as well. However, the presence of novel enzymes, the lack of $\mathrm{AO}$, and the particularly efficient FDR activity imply a different, as yet unknown, regulatory mechanism for methanol assimilation as well as for endo- and exogenous formaldehyde biodegradation. Also, little is known about any possible link between Fd degrading enzymes and other xenobiotic-metabolizing activities. These topics appear to be challenging problems for future studies.

\section{CONCLUSIONS - FUTURE PERSPECTIVES FOR BIOTECHNOLOGICAL APPLICATIONS OF THE ISOLATED STRAIN}

Several biochemical and physiological features of the Trichosporon strain presented in this article indicate that the application potential of this yeast in biotechnology is very promising. In particular, there is growing interest in the use of microbial atypical enzymatic pathways for environmental biotechnology efforts. The isolated strain can adapt to extreme levels of various xenobiotics: phenol, formaldehyde, methanol and petroleumderived hydrocarbons. In such environments this yeast induces metabolic potential enabling it to biodegrade at least some of these compounds. Thus, the strain seems to be a suitable microorganism for the treatment of heavy-load wastewaters originating from chemical installations. When grown as monoculture, it could be used as a biofilter to treat undiluted wastewaters since it can tolerate certain environmental contaminants at the highest concentrations generated by technological processes. For example, formaldehyde in industrial effluents can reach the level of $10 \mathrm{~g} / 1$ (Gonzales-Gil et al., 2000) and phenol, after chemical pretreatment of wastewaters, $0.4 \mathrm{~g} / 1$ (Godjevargova et al., 2003). The use of the strain as a component of activated sludge or as an organism integrated with specialized microbial consortia (Glancer-Soljan et al., 2001) for wastewater treatment and bioremediation of oil-polluted soil should also be considered.

\section{Acknowledgements}

We thank Ms. Natalia Malachowa (Jagiellonian University) for her help in molecular analyses of the yeast. We also greatly appreciate kind and helpful comments of Professor Wouter J. Middelhoven (Wageningen University) and Professor Robert A. Schwartz (New Jersey Medical School, UMDNJ). The work was financially supported by the State Committee for Scientific Research, grants no. 3 P04G 058 23 and no. 2 P04G 06227.

\section{REFERENCES}

Alexieva Z, Ivanova D, Godjevargova T, Atanasov B (2002) Degradation of some phenol derivatives by Trichosporon cutaneum R57. Process Biochem 37: 1215-1219.

Bardana EJ Jr, Montanaro A (1991) Formaldehyde: an analysis of its respiratory, cutaneous, and immunologic effects. Ann Allergy 66: 441-452.

Dzirba J, Gren I, Rudzinska M, Labuzek S (2006) Degradation of phenol by free and immobilized mixed cultures of Pseudomonas strains. Acta Biochim Polon 53 (Suppl): 179.

Eiroa M, Kennes C, Veiga MC (2004a) Formaldehyde biodegradation and its inhibitory effect on nitrification. $J$ Chem Technol Biotechnol 79: 499-504.

Eiroa M, Kennes C, Veiga MC ( 2004b) Formaldehyde and urea removal in a denitrifying granular sludge blanket reactor. Water Res 38: 3495-3502.

Eiroa M, Kennes C, Veiga MC (2005a) Simultaneous nitrification and formaldehyde biodegradation in an activated sludge unit. Bioresour Technol 96: 1914-1918.

Eiroa M, Vilar A, Kennes C, Veiga MC (2005b) Formaldehyde biodegradation in the presence of methanol under denitrifying conditions. J Chem Technol Biotechnol 81: 312-317.

Fell JW, Boekhout T, Fonseca A, Scorzetti G, Statzell-Tallman A (2000) Biodiversity and systematics of basidiomycetous yeasts as determined by large-subunit rDNA D1/D2 domain sequence analysis. Int J Syst Evol Microbiol 50: 1351-1371.

Fujita SI, Senda Y, Nakaguchi S, Hashimoto T (2001) Multiplex PCR using internal transcribed spacer 1 and 2 regions for rapid detection and identification of yeast strains. J Clin Microbiol 39: 3617-3622.

Glancer-Soljan M, Soljan V, Dragicevic TL, Cacic L (2001) Aerobic degradation of formaldehyde in wastewater from the production of melamine resins. Food Technol Biotechnol 39: 197-202.

Gleeson MA, Sudbery PE (1988) The methylotrophic yeasts. Yeast 4: 1-15.

Godjevargova T, Ivanova D, Alexieva Z, Dimova N (2003) Biodegradation of toxic organic components from industrial phenol production waste waters by free and immobilized Trichosporon cutaneum R57. Process Biochem 38: 915-920.

Gonzalez-Gil G, Kleerebezem R, Lettinga G (2000) Formaldehyde toxicity in anaerobic systems. Water Sci Technol 42: 223-229.

Hamme van JD, Singh A, Ward OP (2003) Recent advances in petroleum microbiology. Microbiol Mol Biol Rev 67: 503-549.

Kaszycki P, Koloczek H (2000) Formaldehyde and methanol biodegradation with the methylotrophic yeast Hansenula polymorpha in a model wastewater system. Microbiol Res 154: 289-296.

Kaszycki P, Tyszka M, Malec P, Koloczek H (2001) Formaldehyde and methanol biodegradation with the methylotrophic yeast Hansenula polymorpha. An application to real wastewater treatment. Biodegradation 12: 169-177.

Kato N, Miyawaki N, Sakazawa C (1982) Oxidation of formaldehyde by resistant yeasts Debaryomyces vanriji and Trichosporon penicillatum. Agric Biol Chem 46: 655661.

Koloczek H, Czechowska K, Petryszak P, Kaszycki P (2004) Biodegradation of oil derivatives with methylotrophic yeast isolates. Possible enzymatic links between the methylotrophic and hydrocarbon-degrading path- 
ways. Bioremediation of soils contaminated with aromatic compounds: Effects of rhizosphere, bioavailability, gene regulation and stress adaptation. NATO Advanced Research Workshop, 1-3 July 2004, Tartu, Estonia.

Kurtzman CP (2000) Systematics and taxonomy of yeasts. In Dimorphism in Human Phatogenic and Aphatogenic Yeasts (Ernst JF, Schmidt A, eds) vol. 5, pp1-14, Contrib Microbiol, Basel, Karger.

Laemmli UK (1970) Cleavage of structural proteins during the assembly of the head of bacteriophage T4. Nature 227: 680-685.

Lowry OH, Rosebrough NJ, Farr AL, Randall RJ (1951) Protein measurement with the Folin phenol reagent. $J$ Biol Chem 193: 265-275.

MacGillivray AR, Shiaris MP (1993) Biotransformation of polycyclic aromatic hydrocarbons by yeasts isolated from coastal sediments. Appl Environ Microbiol 59: 1613-1618.

Maidan NN, Gonchar MV, Sibirny AA (1997) Oxidation of exogenous formaldehyde in methylotrophic and non-methylotrophic yeast cells. Biochemistry (Mosc) 62: 636-640.

Michalik J (1975) Methanol in the metabolism of microorganisms. Post Mikrobiol 14: 93-109 (in Polish).

Michalik J, Raczynska-Bojanowska K (1976) Oxidation of methanol by facultative and obligate methylotrophs. Acta Biochim Polon 23: 375-386.

Middelhoven WJ, Scorzetti G, Fell JW (2001) Trichosporon porosum comb. nov., an anamorphic basidiomycetous yeast inhabiting soil, related to the loubieri / laibachii group of species that assimilate hemicelluloses and phenolic compounds. FEMS Yeast Res 1: 15-22.

Middelhoven WJ, Scorzetti G, Fell JW (2004) Systematics of the anamorphic basidiomycetous yeasts genus Trichosporon Behrend with the description of five novel species: Trichosporon vadense, T. smithiae, T. dehoogii, T. scarabaeorum and T. gamsii. Int J Syst Evol Microbiol 54: 975-986.

Mirdamadi S, Rajabi A, Khalilzadeh P, Norozian D (2005) Isolation of bacteria able to metabolize high concentrations of formaldehyde. World J Microbiol Biotechnol 21: 1299-1301.

Nash T (1953) The colorimetric estimation of formaldehyde by means of the Hantzsch reaction. Biochemistry 55: 416-421.

Qu M, Bhattacharya SK (1997) Toxicity and biodegradation of formaldehyde in anaerobic methanogenic culture. Biotechnol Bioeng 55: 727 - 736.

Reiser J, Glumoff V, Ochsner UO, Fiechter A (1994) Molecular analysis of the Trichosporoncutaneum DSM 70698 $\arg A$ gene and its use for DNA-mediated transformations. J Bacteriol 176: 3021-3032.

Sampaio JP (1999) Utilization of low molecular weight aromatic compounds by heterobasidiomycetous yeasts: taxonomic implications. Can J Microbiol 45: 491-512.

Santos VL, Linardi VR (2001) Phenol degradation by yeast isolated from industrial effluents. J Gen Appl Microbiol 47: $213-221$.

Satyanarayana T, Raghukumar C, Shivaji S (2005) Extremophilic microbes: Diversity and perspectives. Curr Sci 89: 78-90.

Schwartz RA (2004) Superficial fungal infections. Lancet 364: 1173-1182.

Sibirny AA, Titorenko VI, Gonchar MV, Ubiyvovk VM, Ksheminskaya GP, Vitvitskaya OP (1988) Genetic control of methanol utilization in yeasts. J Basic Microbiol 28: 293-319.

Sietmann R, Hammer E, Schauer F (2002) Biotransformation of biarylic compounds by yeasts of the genus Trichosporon. System Appl Microbiol 25: 332-339.

Spencer JFT, Ragout de Spencer AL, Laluce C (2002) Nonconventional yeasts. Appl Microbiol Biotechnol 58: 147156.

Sugita T, Nishikawa A, Shinoda T (1998) Identification of Trichosporon asahii by PCR based on sequences of the internal transcribed spacer regions. J Clin Microbiol 36: 2742-2744.

Sugita T, Nishikawa A, Ikeda R, Shinoda T (1999) Identification of medically relevant Trichosporon species based on sequences of internal transcribed spacer regions and construction of a database for identification of Trichosporon identification. J Clin Microbiol 37: 1985-1993.

Sugita T, Takashima M, Nakase T, Ichikawa T, Ikeda R, Shinoda T (2001) Two new yeasts, Trichosporon debeurmannianum sp. nov. and Trichosporon dermatis sp. nov., transferred from Cryptococcus humicola complex. Int J Syst Evol Microbiol 51: 1221-1228.

Sugita T, Takashima M, Nakase T, Ichikawa T, Shinoda T, Nishikawa A (2002) A basidiomycetous anamorphic yeast, Trichosporon terricola sp. nov., isolated from soil. J Gen Appl Microbiol 48: 293-297.

Tsai SC, Tsai LD, Li YK (2005) An isolated Candida albicans TL3 capable of degrading phenol at large concentration. Biosci Biotechnol Biochem 69: 2358-2367.

Walker GM (1998) Yeast Physiology and Biotechnology. John Wiley \& Sons, Chichester, New York.

Yang Z, Suzuki H, Sasaki S, Karube I (1996) Disposable sensor for biochemical oxygen demand. Appl Microbiol Biotechnol 46: 10-14. 